\title{
Spiritual Abuse in Christian faith settings: Definition, policy and practice guidance.
}

\begin{tabular}{|r|l|}
\hline Journal: & The Journal of Adult Protection \\
\hline Manuscript ID & JAP-03-2018-0005.R2 \\
\hline Manuscript Type: & Research Paper \\
\hline Keywords: & christianity, policy, practice, spiritual, abuse, faith \\
\hline
\end{tabular}

SCHOLARONE ${ }^{m}$

Manuscripts 


\section{Spiritual Abuse in Christian faith settings: Definition, policy and practice guidance.}

\section{Purpose}

A previous publication in this journal reported the findings of a 2013 survey into people's experiences of membership of a Christian church in the UK (Oakley and Kinmond, 2014). A major finding of this survey was that many people said they had been 'harmed' by their experience with some labelling it as 'Spiritual Abuse'(SA). Respondents in the 2013 study also stressed the importance of developing safeguarding policy and practice in this area. The current paper explores the findings of a more extensive survey conducted in 2017 which aims to identify people's understanding of SA some four years after the initial work and within a context of some discussion and uncertainty around the term itself. The study also aims to assess the current status of safeguarding policy and practice in SA perpetrated against individuals in the Christian church in the UK. A secondary aim of the study is to ascertain how far understandings, policy and practice have developed since the initial survey was conducted. It is emphasised that the authors do not assert that spiritual abuse is perpetrated solely in the Christian church. However, as this is their personal religious background it is the focus of this work.

\section{Design/methodology/approach}

A mixed methods online survey of Christians, Church attendees and members of Christian organisations was conducted in 2017. Data were analysed using descriptive statistics, thematic and content analysis.

\section{Findings}

A clear definition of spiritual abuse is required. There is an ongoing need to develop policy and practice in the area of spiritual abuse in order to respond effectively to those who have these harmful experiences.

\section{Research limitations/implications}

This work has been conducted within the Christian faith community and thus, represents only this faith context. Accordingly, it is research with a specific group. The work would usefully be expanded to other faith contexts. 


\section{Practical Implications}

People are still being harmed by experiences in the Christian church. Safeguarding policy and practice in the area of spiritual abuse needs to be developed in the immediate future.

\section{Social Implications}

Those working in statutory agencies, faith and community contexts need to develop an understanding of spiritual abuse.

\section{Originality/value}

This is the largest survey conducted on the topic of spiritual abuse in the Christian faith to date in the UK.

\section{Keywords}

Spiritual abuse, Christianity, policy, practice, definition.

\section{Article Type}

Research paper

\section{$\underline{\text { Introduction }}$}

This paper presents the findings of a recent survey into people's experiences in Church, looking specifically at the issue of Spiritual Abuse (SA). The study aims to identify people's understanding of SA within a context of discussion and uncertainty around the term itself. The study also aims to assess the current status of safeguarding policy and practice in SA in the Christian church. The current paper follows on from earlier work (Oakley \& Kinmond, 2014) which reported findings of a more general survey that explored people's experiences of being a member of a Christian church in the United Kingdom (UK) in a context of issues of safeguarding and policy. In total 502 people aged between 18 to over 70 years, from a wide range of church denominations, completed this initial survey. An unexpected finding in the first survey was the level of harm respondents reported having experienced in church membership, with 75\% reporting feeling “damaged". Some respondents named their experiences as "Spiritual Abuse" (SA). Most respondents were uncertain how to define SA but the following issues were suggested: a focus on coercion, control, manipulation, misuse of scripture and misuse of power by Church leaders. 
Leading on from the initial survey the work reported in this paper details a subsequent piece of work undertaken by the authors which focuses on SA; exploring understandings of SA and the features of an effective response to a disclosure together with suggestions for policy, training and practice development in the area. This paper reports the findings of the recent survey but also reflects upon how these findings compare to the initial work. It should be noted that this paper focuses upon the Christian faith, but feedback at conference presentations supports the notion that SA is evidenced across faiths and future research could expand this work to include other faiths.

\section{Safeguarding adults in the faith context}

In a previous paper focused on 'safeguarding adults in the Christian faith context' some of the authors explored the broader safeguarding law and policy for adults and the implications for Christian contexts (Oakley et al., 2016). It was argued that The Care Act (2014) embedded a person-centred approach which promotes safeguarding as 'every body's business (Romeo, 2015:206) which demands both individuals and organisations to work together to prevent harm. Christian faith agencies are amongst those required to respond to the Care Act (2014). Part of this response is in recognising the 'making safeguarding personal' (MSP) guidance (LGA, 2015) which promotes partnership working to empower adults to operate choice and control in safeguarding matters. MSP changes the emphasis from an individual as 'vulnerable' to one who is key in the safeguarding process (Oakley et al., 2016).

Christian faith agencies offer a multitude of services and support to adults in addition to regular worship meetings. In our previous paper recommendations were made for the development of 'robust safeguarding policies and practice' in faith contexts in order to safeguard adults who attend. (Oakley et al., 2016). This discussion of SA occurs within this wider safeguarding context.

\section{Background}

SA is a relatively new term in literature, policy and discourse. One of the first published texts using it was Johnson and VanVonderen's (1991) book entitled 'The subtle power of Spiritual Abuse'. Although this book represented a new body of literature employing the term SA, there is a history of writing around coercive control and the abuse of power across Christian faith contexts (e.g. Baxter, 1956; Plowman, 1975; Enroth, 1992). A review of work suggest 
the term SA originated in the United States of America but then spread to other areas of the world including Australia and the UK (Ward, 2011, Davis-Weir 2015, Diederich 2017).

In recent years there has been development in policy in this area, with an increasing number of Christian safeguarding policy documents now including SA 'for example' - Safeguarding Children and young people (2010); Protecting all God's children (2010). Testament to the currency of the discussion and debate around SA in the Christian arena is found in the series of articles published in popular Christian media (Evangelical Alliance, 2018; Kandiah, 2018; Norman-Walker, 2018; Oakley, 2018). The focus of these articles was a debate around the terminology and definition of SA.

Indeed, there remains a deadlock presently regarding a singular, accepted definition of SA acceptable to policy makers, academics, theologians and those who have experienced this form of abuse. Yet, a clear, shared definition is surely required for a positive movement forward in research, understanding, awareness, policy and practice.

As stated above, currently there are a range of definitions being used by various people in different contexts with possibly the most commonly quoted sources being Johnson and VanVonderen (2005) who state,

"Spiritual abuse is the mistreatment of a person who is in need of help, support or greater spiritual empowerment, with the result of weakening, undermining or decreasing that person's spiritual empowerment";

And (Oakley and Kinmond, 2013) who define SA as "Spiritual abuse is coercion and control of one individual by another in a spiritual context. The target experiences spiritual abuse as a deeply emotional personal attack. This abuse may include: manipulation and exploitation, enforced accountability, censorship of decision making, requirements for secrecy and silence, pressure to conform, misuse of scripture or the pulpit to control behaviour, requirement of obedience to the abuser, the suggestion that the abuser has a 'divine' position, isolation from others, especially those external to the abusive context.

In these referenced texts, the authors called for SA to be considered as a separate category of abuse (Oakley and Kinmond, 2014). However, following on from recent discussions and debate, together with development in relevant policy and further research in both SA and also 
Domestic Violence and Abuse (DVA), arguably, this call deserves further consideration. It will be explored further here.

In 2015 the government definition of DVA developed to include coercive control. Currently, the focus on coercive control only applies to intimate relationships or to members of the same family who live together. However, there is a growing interest in the role of coercive control across all forms of abuse. This includes SA with some recent writing arguing for the recognition that SA includes coercive and controlling behaviour (Oakley, 2018, CCPAS, 2018). In the same way that it is now recognised that DVA can exist without physical or sexual content it is important to understand that SA can exist as a form of psychological or emotional abuse devoid of physical or sexual abuse. Indeed, the psychological impact of SA has been reported by survivors to be extremely negative and harmful. In response, there has been some focus on developing safeguarding and interventions in ongoing work with the Church of England and Churches' Child Protection Advisory Service CCPAS.

Psychological or emotional abuse are types of abuse listed in the care and support statutory guidance (HMGov, 2018) for the recent Care Act (2014). Behaviours associated within this category include 'causing mental distress, humiliation, blaming, the use of threats of harm and being deprived of social contact'. All these factors are relevant to SA. However, there are also some very distinct and specific characteristics of SA that differentiate it from other forms of abuse such as DVA, psychological abuse or solely coercive control. SA involves control through the use of scripture, the assertion of God as complicit in the control and manipulation experienced, threats of spiritual consequences for non-compliance with behavioural demands or expectations of the perpetrator and the idea that someone has been appointed by God and therefore is above question or reproach, and as such holds a divine position. In these ways, despite sharing some characteristics with psychological and emotional abuse, SA has distinctive features, as detailed above, which legitimise this being considered as a sub-category of psychological and emotional abuse.

At the time of administering the initial survey there was a paucity of academic published work on SA (Ward, 2011). SA was beginning to emerge as an issue for consideration in safeguarding policy and practice in churches. However, despite policies in church which focused on child protection (Protecting all God's children, 2010) and protection of vulnerable adults there remained limited awareness and understanding of the reality of SA or how to implement relevant safeguarding policies. Suggestions for practice were frequently to report 
concerns to authorities or a senior member of the Church; both of which may be problematic for individuals affected by SA. Indeed, earlier work (Oakley and Kinmond, 2013) demonstrates that many people are unlikely to report their experiences to authorities outside church for fear of them being misunderstood; nor are they likely to seek support from the church as this is the site of their abuse.

The current study seeks to explore policy, practice and response and to compare the findings to the earlier research to assess progress in the area of SA.

\section{The study}

This study was commissioned by Churches Child Protection Advisory Service (CCPAS). It employed a mixed methods approach (Cresswell \& Plano Clark, 2007) collecting both qualitative and quantitative data via a questionnaire distributed on SurveyMonkey, live for 8 weeks from January 30th, 2017 to March 30 ${ }^{\text {th }}, 2017$. The questionnaire consisted of closed and open questions designed to identify current understandings of SA, give details of training people had undertaken, and to offer suggestions for effective responses to disclosures, with recommendations also for policy and practice.

\section{Sample}

Participants were recruited via a number of methods; through CCPAS membership; though distribution of the survey link and invitation email via the National Task and Finish Group for Spiritual Abuse in the Church of England and via denomination safeguarding contacts at the Christian Forum for Safeguarding. Relevant pages on the social networking site Facebook were also used to advertise the survey.

Inclusion criteria were 'membership of the Christian faith, Church attender or membership of a Christian organisation'. To answer the questionnaire respondents were advised that they needed to have heard of the term 'Spiritual Abuse'. The sample were self-defining.

In total 1591 respondents completed the survey, 1002 of whom identified as having a personal experience of SA. $69 \%$ of the sample was female and $31 \%$ male. There was representation from across the age range but the majority, who answered this question, were aged between 30 and 69 years Respondents came from a range of denominational 
backgrounds. However, the majority were from the Anglican, Baptist, Independent and Pentecostal traditions. The category of 'other' is quite significant at $17.85 \%$ - the majority of respondents in the 'other' category identified as Quakers (This information is presented in Table 1 below).

\begin{tabular}{|l|l|l|l|}
\hline $\begin{array}{l}\text { Age Range of } \\
\text { respondents in } \\
\text { years }\end{array}$ & $\begin{array}{l}\text { \% of } \\
\text { respondents }\end{array}$ & $\begin{array}{l}\text { Denominational of } \\
\text { affiliation of } \\
\text { respondents }\end{array}$ & $\begin{array}{l}\text { of } \\
\text { respondents }\end{array}$ \\
\hline $18-20$ & 0.41 & Anglican & 15.13 \\
\hline $21-29$ & 6.73 & Methodist & 1.31 \\
\hline $30-39$ & 15.44 & Catholic & 1.17 \\
\hline $40-49$ & 20.59 & Baptist & 12.17 \\
\hline $50-59$ & 28.28 & Independent & 17.06 \\
\hline $60-69$ & 20.73 & Pentecostal & 15.54 \\
\hline 70 or older & 7.14 & URC & 6.74 \\
\hline Prefer not to & 0.69 & 'New Churches' & 9.08 \\
\hline answer & & Orthodox & 0.07 \\
\hline & & Prefer not to answer & 4.54 \\
\hline & & Other & 17.19 \\
\hline
\end{tabular}

Table 1 - Age of and denominational affiliation of respondents

\section{Ethics}

As this research area is potentially sensitive the researchers were cognisant of the need to work overtly within their professional body's ethical code. Additional consideration was also required for the demands of on-line research. Accordingly, the survey was designed in accordance with the British Psychological Society (BPS) ethical guidelines for conducting internet mediated research (BPS, 2017) and the Code of Human Research Ethics (BPS, 2011) plus the British Association of Counselling \& Psychotherapy (BACP) ethical framework. It was approved by the Bournemouth University social sciences ethics committee in December 2016. Participation was voluntary, with no financial inducement offered. 
The principle of 'Respect for the Autonomy and Dignity of Persons' (BPS, 2011) was deemed to be an important ethical consideration in this research and thus, the researchers gave much attention to 'obtaining valid consent' (BPS, 2013). The first page of the online survey consisted of an information sheet and consent form. Respondents were informed that completion of the survey denoted their consent to participate. Every question offered the option 'prefer not to answer' or to omit answering the question and pass on to the next. Also, respondents were given the option to leave the survey and not submit their responses.

At the end of the survey respondents were asked for consent to include their data and whether they consented to the use of anonymised direct quotes. 293 respondents chose to withdraw all their data, 28 chose to allow their data to be used but not their anonymised quotes. Only data with participant consent is included in this study.

A further consideration within this principle is that of 'anonymity and confidentiality' (BPS, 2013). Arguably, an on-line platform offers potential benefits in participants perceiving anonymity especially with work in sensitive areas (Nicholas, et al 2010) participants can feel freer to share information they may not feel able to do in face-to-face interaction. However, the researchers were mindful that participants may give detailed information. In order to reduce the possibility of identification the collection of IP addresses was disabled in the survey and email addresses were not collected. At the end of the survey participants were provided with the CCPAS helpline details if they wished to obtain help or support following the survey completion.

\section{Data Analysis}

Quantitative data were analysed using the Survey Monkey descriptive statistics package. An inductive thematic analysis (Braun and Clarke, 2006) was conducted on the qualitative data using Nvivo and then a content analysis of particular words or phrases was conducted to assess the frequency of certain responses. It is acknowledged that both researchers' Christian beliefs necessarily impacted upon the analysis as background influences experience and perception; however, as Guillemin and Gillam, (2004 p276) note, "Reflexivity in research is ... a process of critical reflection”. Accordingly, we took “..a step back" (Guillemin and Gillam, 2004 p278) and returned to the analysis several times both individually and collaboratively, before committing the themes to a computer based data analysis package. 


\section{$\underline{\text { Findings }}$}

922 respondents described where they had heard about SA. Their answers demonstrate that $55 \%$ had heard this term within their Church or Christian organisation, $41 \%$ from published articles and newspapers, $37 \%$ online, $36 \%$ from friends or family, $28 \%$ in training or at conferences and $13 \%$ on the TV or radio. $22 \%$ indicated they had heard of SA from 'other sources'. The most prevalent answer in this category was that respondents had personal experience of SA. Other answers included those who encountered this through their work role and some identified books and text sources of information.

In the findings reported below respondents' comments are given in italics, sub-themes comprising the superordinate theme under discussion are in bold.

\section{Definitions and characteristics of spiritual abuse}

$80 \%$ of respondents stated that they were confident that they knew what the term SA means. There were 942 open text comments in response to the statement - 'I would describe spiritual abuse as....' 626 comments referred to religious or spiritual belief as a central component to spiritual abuse. It was usually the employment of this belief leading to harm of another that was central to definitions offered. For example,

Using religious backing to defend bullying, belittling, or causing harm to others. It can also be someone using an individual's spirituality against them.

415 respondents noted coercion and control as defining features of spiritual abuse with comments such as Dominating, abusing and controlling others. Manipulation and pressuring of individuals $(\mathrm{n}=207)$ were also common features of definitions,

Manipulation of another person's thoughts, feelings belief systems, "Emotional manipulation under the guise of righteousness.

Perhaps importantly, many respondents noted features of SA that distinguish it from other forms of emotional abuse. These included Control through the use of religious texts and scripture $(n=172)$, with comments such as 
The misuse of scripture to control and manipulate, the act of using Biblical scripture and one's position within the Church as a means to exploit or coerce an individual to do what they want in order for them to gain emotionally, physically or financially; or to control that individual.

Other responses focused on the use of a 'divine rationale' for mistreatment of others $(n=140)$, which often incorporated portraying God as being in agreement with, or the reason for, the harmful behaviour. Examples of responses include

promulgating image of God as watching and waiting to trip up sinners and agreeing in every respect with abuser's attitudes and actions., harm caused by being made to feel not a good enough Christian/not a proper Christian or that your identity or behaviour is somehow unacceptable to God.

Although respondents provided descriptions of what they understood SA to be, they also requested the development of an agreed definition to provide clarity. As one respondent comments

I think that this area of spiritual abuse is not well defined and therefore a clearer definition would be helpful",

another requests...

$A$ "fag packet" definition of abuse so anyone in a church context can recognise it.

There was some discussion in the responses about whether SA should be a separate category. Respondents were divided on their views with one commenting “whenever I hear the term 'spiritual abuse' it gives me pause, not because I don't think people suffer abuse in Christian organisations, but because I'm not sure it's a separate category".

Others however, were clear that it merits a category of its own.

A further interesting message in the study was that Church leaders $(n=100)$ can and do experience spiritual abuse and that it is not simply an abuse perpetrated by those in positions of power and leadership. As one respondent reflected

I think it is worth noting that although much spiritual abuse is from leader to church members, that also leaders can be abused, with another stating "think people assume the abuser is usually the person with more 'power' e.g. The church leader but ... 
church leaders are often not very protected from being abused themselves from members of their church.

It is clear from this that in developing an understanding of SA recognition must be given that anyone can experience this, regardless of Church position.

\section{Policy}

In addition to requesting a clear definition of SA respondents stated that there also needs to be clear policy and procedure $(n=133) .1002$ respondents answered the question asking if their Church or Christian organisation had a safeguarding policy which includes SA 33\% stated they their church's safeguarding policy includes SA, 26\% said theirs does not, 39\% were not sure and $2 \%$ preferred not to answer. This demonstrates a lack of safeguarding policy around this issue.

Respondents suggested that policy should include a clear procedure for responding to a disclosure.

A clear policy, with precise steps on what should be done.

This procedure needs to be explained carefully to the individual disclosing, so they are aware of actions to follow. As one respondent stated, there needs to be a

...clear process for handling any claim in order, to be honest of what will happen now. Once there has been disclosure respondents were clear that this should lead to action $(\mathbf{n}=98)$. One action maybe a referral to the safeguarding officer if they did not hear the disclosure; other responses included the importance of referring on for investigation. As one respondent argued, there is a need

...to immediately refer to a safeguarding officer for advice and there should be ...An investigation by a body that understands the church.

Some responses noted that any action should be discussed with the individual disclosing and that they should be involved in the decision-making process,

Asking the individual whether or how they would like to proceed - e.g. escalation, talking to a counsellor etc.

Some respondents suggested the current lack of policy and procedure leaves people in a difficult position if they want to tell their story or report concerns about others. This difficulty led to some suggestions that there should be a 'whistle blowing' procedure to allow concerns 
to be raised anonymously and to provide some degree of protection for individuals who whistle blow.

There should be confidential channels for raising concerns, and these should be well publicised. Whistle blowers should be protected, not ostracized.

\section{Impact}

Although there were no questions asking respondents to tell personal stories of spiritual abuse, many used the open text comments to provide details of their experiences. The level of damage/harm $(n=96)$ felt, and the impact of the experience was relayed clearly in the responses:

I was absolutely floored because my world started crumbling around me...

Another respondent stated,

So often this is not taken as seriously as physical abuse and yet, to hear someone recognise that it can be just as serious, would help enormously.

Some respondents acknowledged the breadth of the impact, with one commenting, I believe is quite widespread. It MUST be addressed as an issue.

, Some comments showed that work was crucial in this area as awareness $(n=88)$ is still growing and many may not understand or be able to name what they are experiencing. As one respondent stated,

It is possible to have experienced spiritual abuse over a prolonged period of time without realising it.

Other respondents talked of the need for awareness of who is and is not vulnerable to this experience; ,

Ifeel that most safeguarding training focuses on vulnerable people in terms of children, elderly, those with mental health issues etc however I feel that spiritual abuse may include those whom would not usually be classed as vulnerable but become so when they are new to the 'norms' of spiritual organisations.

Even those with professional safeguarding backgrounds have stories of SA, I have worked in safeguarding and child protection for my whole working life yet even I suffered in this way

\section{Discussion}


The findings demonstrate that individuals are identifying their experiences with the term SA. Respondents were able to articulate their understandings and definitions of SA in a much more detailed and clear manner than in the 2013 study. Their discussion of key characteristics of SA included

'religious or spiritual belief as a central component'. 'coercion and control', 'manipulation and pressuring of individuals', 'control through the use of religious texts and scripture', and 'divine rationale for mistreatment of others'.

A further key message of the current study was that SA is not solely perpetrated by those in positions of leadership and that Church leaders have and are experiencing this harm. It is interesting to note that this recognition contrasts with the earlier 2013 study, where most respondents suggested that SA was perpetrated solely by those in positions of Church leadership.

The findings from the current study illustrate a call for an agreed definition of SA to be developed to aid clarity and effective response and intervention. It is of concern that this request is a repetition of the findings of the 2013 study, where confusion over definition and the need for clarity was reported. Whilst there have been a range of definitions in published work (e.g. Blue, 1993; Johnson and VanVonderen, 2005; Nelson, 2015; Deidrech, 2017) there is still not a universally agreed definition of SA.

Recently, there has been discussion of category such that there has been debate about whether SA should be recognised as a category of abuse in its own right or whether it should be considered simply as a form of emotional and psychological abuse. In earlier (Oakley and Kinmond, 2013) the authors argued for the creation of a separate and distinct category of SA. However, reflecting upon recent research, it might usefully be argued that. the statutory categories in existence are broad enough to embrace SA within the accepted understandings and policy framework of emotional and psychological abuse. Emotional and psychological abuse are characterised by repeated patterns of blaming, shaming, intimidation and controlling behaviour (Working Together to Safeguard Children, 2015); all of which are features of SA. Nonetheless, SA occurs in a context of spirituality with the distinct elements of 'divine rationale' for the mistreatment of others plus the use of sacred texts to abuse. The specificity of SA is the religious context in which the abuse occurs and the operationalisation of coercive control, manipulation, exploitation, censorship of decision-making, pressure to conform, enforced accountability, and required obedience and isolation through divine 
position which gives unquestioning authority. Certainly, SA involves emotional and psychological abuse, but it is argued that SA has specific and distinct features and thus, should also be recognised as a sub-category of this more general category of abuse. This resonates with the findings of the research reported in this paper wherein respondents named their experiences not as emotional and psychological abuse, but rather as SA.

On the basis of the argument above a new definition of spiritual abuse has been developed Spiritual abuse is a form of emotional and psychological abuse. It is characterised by a systematic pattern of coercive and controlling behaviour in a religious context. Spiritual abuse can have a deeply damaging impact on those who experience it.

This abuse may include: manipulation and exploitation, enforced accountability, censorship of decision making, requirements for secrecy and silence, coercion to conform, control through the use of sacred texts or teaching, requirement of obedience to the abuser, the suggestion that the abuser has a 'divine' position, isolation as a means of punishment, and superiority and elitism' (Oakley, 2018).

It is important to understand that SA is often only identified during disclosures of other forms of abuse, although it could be argued that many experiences of abuse in faith settings will include elements of SA. It should be noted that SA has also been reported as the sole form of abuse experienced. So, accordingly development of policy and practice in this area should recognise these interfaces.

\section{Policy and practice guidance}

The current and previous survey (Oakley and Kinmond, 2014) illustrate the necessity to develop policy in the area of SA. The findings from the current study demonstrate that although there has been some policy development at a local Church or Christian organisation level there is limited detailed specific policy in this area. Therefore, there is a continued need for policy development.

A further issue highlighted by the recent survey was the need for policy to incorporate clear procedures for responding to a disclosure of SA. These should be explained to anyone making a disclosure. Responses suggested uncertainty about how a disclosure would be responded to and what procedure there was for taking forward complaints. 
A recommendation from the study is to consider the development of a whistleblowing procedure that operates independently from local settings. In this way the individual raising concerns might be protected facilitating further disclosures. However, caution should be sounded as whistle-blowing procedures in areas such as health, have often failed to provide protection and indeed can result in punitive action towards the whistleblower (Waring, 2016). Therefore, if a whistle-blowing process is to be developed it must consider past failures and be developed in line with models of whistle-blowing that have been shown to be effective (Skiveness \& Trystad, 2010).

In a discussion of policy, it is interesting to return to the MSP agenda discussed earlier. The notion of a person-centered approach and safeguarding as a partnership activity (LGA, 2015) has clear merits. Yet caution is advised since SA is an experience of coercion, control and manipulation. In experiences of coercive control autonomy is systematically undermined (Stark 2007 as cited in Hanna, 2009). In this context the notion of being a 'partner in safeguarding' may be incredibly difficult if not impossible. The same care taken to work with other victims of abuse is needed in working with victims of SA, recognising that decisionmaking and choices about referral may be deeply challenging and frightening. For example, Stark (2007 as cited in Hanna, 2009) reflects that women who experience coercive control find it more anxiety provoking to live in a world that is different from their abuser's reality, rather than to stay in it. In seeking to employ the principles of MSP great care must be taken to understand the impact of coercive control on an individual and to enable partnership working that is not distressing or triggering for the victim.

\section{The implications of the impact of experiencing spiritual abuse}

Many respondents described the impact of SA and again noted the damage experienced. The reported impact resonates with other writing in this area (Enroth. 1994, Johnson and VanVonderen, 2005; Deidrech, 2017). In a number of the discussions the respondents suggest that it is precisely because of the depth of damage experienced that policy and practice in this area must develop quickly. The findings also show the need to continue to raise awareness of this issue as individuals may not yet recognise their experiences as abuse. This leaves them encountering harm without an understanding to enable them to identify and seek help in an effective manner. There should not be an assumption about vulnerability to SA. The respondents' answers clearly indicate that anyone can have this experience indeed, professionals in the area of safeguarding recounted their own stories. 
It is important to explore the impact of experiencing SA in much greater depth. However, this is beyond the limits and remit of the current paper if true consideration is to be given to survivors' stories. Therefore, impact will be addressed in future publications.

\author{
Summary \\ The results of the survey illustrate the need for a clear definition of SA. They also show that \\ policy and practice development and guidance in this area continues to be a necessity. It is \\ somewhat discouraging to realise that many of the messages in this article mirror or extend \\ those from the previous survey as it suggests that little has been undertaken to protect those \\ being harmed by this form of abuse. Therefore, it is of great importance that action is taken to \\ ensure that in four years' time these messages are not repeated. Rather, that policy, practice, \\ intervention and response to SA has developed. Further, that people working within the field \\ will know where to sign-post people to for support; those needing to report it will have a \\ clear structure and guidance within which to work. Finally, and importantly, that people \\ experiencing SA will know that their experience is real and acknowledged with effective \\ support readily available.
}

\title{
References
}

Baxter, R. (1981), The Reformed Pastor, The Banner of Truth Trust.

Blue, K. (1993), Healing Spiritual Abuse - How to Break Free from Bad Church Experiences Intervarsity Press, Illinois.

Braun, V. and Clarke, V. (2006), "Using thematic analysis in psychology", Qualitative Research in Psychology, 3 (2). pp. 77-101.

British Psychological Society. (2011)," Code of Human Research Ethics”, available at http://www.bps.org.uk/sites/default/files/documents/code of human research ethics.pdf (accessed 12 December 2017)

British Psychological Society. (2017), "Ethics Guidelines for Internet-mediated Research, available at https://www.bps.org.uk/news-and-policy/ethics-guidelines-internet-mediatedresearch-2017 (accessed 12 December 2017)

Churches Child Protection Advisory Service. (2018). Spiritual Abuse. A position paper, available at http://files.ccpas.co.uk/documents/spiritual-abuse-position-statement.pdf (accessed 28 February, 2018). 
Church House Publishing. (2010), “Protecting All God's Children”, available at https://www.churchofengland.org/sites/default/files/2017-11/protectingallgodschildren.pdf poli (accessed 8 November 2017)

Creswell, J. \& Plano Clark, V. (2007), Designing and conducting mixed methods research, Thousand Oaks, CA: Sage.

Department of Education. (2015), "Working Together to Safeguard Children - Glossary: Emotional Abuse", available at http://www.workingtogetheronline.co.uk/glossary/emo abuse.html (accessed 12 November, 2017).

Davis-Weir, Y. (2015), Spiritual Abuse: Learning and overcoming spiritual abuse in the church and home, WestBow Press.

Deiderich, F.R. (2017), Broken Trust: A Practical Guide to Identify and Recover from Toxic Faith, Toxic Church, and Spiritual Abuse, BISAC

Department of Health. (2014), Care and Support Statutory Guidance Issued Under the Care Act 2014, London: HMSO

Enroth, R. (1992), Churches that Abuse, Zondervan, Grand Rapids MI:

Enroth, R.M. (1994), Recovering from Churches that abuse, Zondervan, MI:.

Evangelical Alliance (2018), Reviewing the Discourse of 'Spiritual Abuse': Logical Problems and Unintended Consequences, available at http://www.eauk.org/currentaffairs/media/press-releases/upload/Reviewing-the-Discourse-of-Spiritual-Abuse.pdf (accessed on March 1 2018)

Guillemine, M., Gillam, L. (2004), Ethics, Reflexivity, and "Ethically Important Moments" in Research, Qualitative Inquiry, Vol.10, No 2 pp. 261-280

DOI: $10.1177 / 1077800403262360$

Hanna, C (2009), The Paradox of Progress: Translating Evan Stark's Coercive Control Into Legal Doctrine for Abused Women, Violence Against Women, Vol.15, No12, pp. 1458-1476.

Home Office. (2015), "Domestic Violence and abuse", available online from https://www.gov.uk/guidance/domestic-violence-and-abuse (accessed on January 72017 )

Johnson, D \& Van Vonderen, J. (2005), The Subtle Power of Spiritual Abuse; Recognizing and Escaping Spiritual Manipulation and False Spiritual Authority Within the Church, Bethany House Publishers, Minnesota, USA.

Kandiah, K. (2018), “Does the Church's first spiritual abuse verdict give critics a new weapon?"Christianity Today, accessed at https://www.christianitytoday.com/ct/2018/januaryweb-only/spiritual-abuse-church-england-guilty-verdict-ccpas-survey.html (accessed on 21 February 2018)

LGA/ADASS (2013) Making Safeguarding Personal, Local Government Association, London. 
Nelson, S. (2015), Spiritual abuse: Unspoken Crisis, Geeky Christian

Nicholas, D, Lach, L, King, G, Scott, M, Boydell, K, Suawatzky, B, Resiman, J, Schippel, E., Young, N. (2010). "Contrasting internet and face-to-face focus groups for children with chronic health conditions: Outcomes and participant experiences", International Journal of Qualitative Methods, Vol. 9, pp. 105- 121

Norman-Walker, A. (2018), "Spiritual Abuse - A Pandora's Box" available at https:/viamedia.news/2018/01/28/spiritual-abuse-a-pandoras-box/ (accessed on 20 February 2018)

Oakley, L.R. (2018) Understanding spiritual abuse. Church Times available at https://www.churchtimes.co.uk/articles/2018/16-february/comment/opinion/understandingspiritual-abuse (accessed on 20 February 2018).

Oakley, L., Bass, S., Fenge, L. and Humphreys, J. (2016). "Exploring the complexities of understanding vulnerability and adult safeguarding within Christian Faith Organisations", Journal of Adult Protection, Vol. 18, No. 3, pp. 172-183.

Oakley, L.R. and Kinmond, K. (2013). Breaking the Silence on Spiritual Abuse. Palgrave McMillian, Basingstoke.

Oakley, L.R. and Kinmond, K.S. (2014) Developing safeguarding policy and practice for Spiritual Abuse, Journal of Adult Protection, Vol. 16, No. 2, pp. 87-95.

Plowman, E.E. (1975), The Deepening Rift in the Charismatic Movement. Christianity Today, pp. 65-66.

Romeo, L. (2015), "Social work and safeguarding adults", The Journal of Adult Protection, Vol. 7, No3 pp. 205-207

Skiveness, M. and Trystad, S.C. (2010), When whistle-blowing works: The Norwegian case, Human Realtions, Vol. 63 No7, pp 1071-1097

The Methodist Church. (2010), "Safeguarding adults", available at http://www.methodist.org.uk/downloads/safe-update-4-1110-adults.pdf (accessed on 8 November, 2017).

The Methodist Church. (2010), "Safeguarding children and young people", available at http://www.methodist.org.uk/downloads/safe-update-3-1110-childrenandyoungpeople.pdf (accessed on 8 November, 2017).

Ward, D.J. (2011), The Lived Experience of Spiritual Abuse, Mental Health, Religion \& Culture, Vol.14, No. 9, pp. 899-915.

Waring, J. (2016), When Whistle-blowers become the Story: The Problem of the 'Third Victim': Comment on "Cultures of Silence and "Cultures of Voice: The Role of Whistleblowing in Healthcare Organisations, International journal of health policy and management, Vol.5, No 2, pp. 133-135. 
2

3

4

5

6

7

8

10

11

12

13

14

15

16

17

18

19

20

2

22

23

24

25

27

28

29

30

31

32

33

34

35

36

37

39

40

41

42

43

44

45

46

47

48

49

50

51

52

53

54

55

56

57

58

59

60 